\title{
Differences of English and Chinese as Written Languages and Strategies in English Writing Teaching
}

\author{
Ying Wang \\ College of Foreign Languages, Hebei United University, Tangshan, China \\ Jing Chen \\ College of Foreign Languages, Hebei United University, Tangshan, China
}

\begin{abstract}
The size of both the United States and China guarantees that many people will communicate in English and Chinese. But those two common languages do not guarantee perfect communication in writing practice for several reasons. This paper explores the factors resulting in non-understandable communication of English and Chinese as written language, and some strategies applied by English teachers when training students' English writing.
\end{abstract}

Index Terms - differences, English, Chinese, written language, strategies

No one knows exactly how many languages are used in today's world. According to one estimate, there are about 3,000 to 4,000 spoken languages. Each differs in sound, grammar, and sentence construction as well as writing style. English and Chinese, which are the most commonly used languages in the world have some factors that influence a good understanding in oral and written communication both in and between these two languages. Especially in business writing, there are some differences in writing style that attract our attention.

\section{DifFerences Between English AND Chinese Thinking Mode}

The thinking patterns are one of the most important cues in culture. It is closely related to cultures and embodies the characteristics of cultural psychology. "The ways of thinking is quite different, actually, people live in certain area have their own way of thinking. It connects to various kinds of factors, such as geography, history, nation and so on. The ways of thinking are the important reason of cultural difference. It includes knowledge, concepts, methods, language and custom and so on."(Deng Yanchang, 1997) Besides, the modes of thinking also are closely related to language. Different modes of thinking are embodied in language. Therefore, the ways of thinking have their own characteristics.

The differences of the thinking patterns between Chinese and English nations can be approached and considered from various viewpoints. Here are but a few instances for illustration.

\section{A. Visual Thinking VS Rational Thinking}

The visualized thinking mode, or empirical synthesizes thinking pattern as Zheng Yanhong (Zheng Yanhong, 2003 ) puts it, establishes the essential difference between the Chinese and the English nation who favors the rational analytic thinking modes. The Chinese is perceptual in their comprehensive thought, but the English and other Western nations may have developed their own rational and analytic thinking modes. The doctrine of "yin and yang as one" in the Chinese philosophy, not denying the opposition though, lays greater emphasis on the aspect of unity. But the separation of God and human in the English and the Westerners philosophy stresses the opposition aspect though not obviously denying the unity. Such difference has been typical of the two different thinking modes. The Chinese stresses the whole and abstract, and the Westerners stress the components and the specific; the Chinese favors synthesis, while the westerners analysis. For instance, when talking about time, the Chinese always start from general units and move on to smaller units, but the English is opposite; and this is also true of their expression of locations. Even in their acquaintance introduction, the Chinese would list the titles (whole) first (from the higher to the lower) before referring to the specific names (individual), but the English would announce the specific name first (individual), then list a succession of duties from the lower to the higher.

\section{B. Generalizing Thinking VS Analytical Thinking}

The Chinese people are concerned more with their own bodies in expressing emotions, so intuition thinking is the main feature of their mode of thought, for which people study objects as a whole and emphasize entirety. Chinese philosophy is systematical naturalism. (Mao Ronggui, 2002) In the English thinking pattern, individualism is greatly emphasized. The English people link their own emotion to planetary influence and the natural elements, so they prefer analytical logic thinking. Target objects are subordinated into small parts in order to be scrutinized, which, of course, may lead them to place the components before the whole when they try to know something. 
That's why in the Chinese language, sense has always been the dominator while the expression forms has been much neglected. But the Westerners, esp. the British nation has always stressed analysis and rationality in their thinking. In their minds, individualism is the prime concern and is always dependent, which has resulted in their dualistic philosophy. Following such perceptions, materials and spirits are separated, just like human and nature, content and form. Here is an example.

S1A: 只有这样才能解决问题。

S1B: Only in this way can you solve the problem.

S1C: The problem can only be solved this way.

S1C is literal translation of the Chinese, as most Chinese learners of English more often than not would do. Such translations reveal that the Chinese learners tend to generalize the English expressions without sufficient attention to the analytical nature of the target language.

\section{Tortuous Thinking VS Straight Thinking}

In the Western philosophy, it has been a lasting convention to pursue alternate contrast in its reasoning, thus establishing a straightforward thinking mode. But the Chinese, on the other hand, have been more accustomed to the harmony and unity of the world, and are more likely to adopt both sides of a matter, thus establishing a tortuous thinking mode. As reflected in their speech, the English tend to stick to the point at the very beginning of the speech, offering a straight and frank theme of the speech before proceeding on to present the relevant details and accompanying situations. That may well account for the syntactic features of a compact head and a long and heavy ending with the emphasis at the front part of the sentences. And the Chinese sentences, due to the speakers' thinking modes, will present the relative information in great detail before hitting upon the theme. For example:

S2A: I met with my middle schoolmate at the entrance of the theater at 7:30 yesterday evening, when I haven't seen for years.

S2B：昨天晚上 7 点半在剧院门口, 我遇到了我多年未见的中学同学。

\section{Backward Thinking VS Predictive Thinking}

It has been found that the Chinese tend to consider matters in predicative order while the English prefers backward thinking. (Zhou Fangzhu, 2004) For instance, the Chinese would usually give reasons before presenting the consequences while the English would rather state the result before giving the causes. E.g.

S3A: She was amazed that he should arrive so soon.

S3B: 他来得真快, 让她惊奇不已。(He had arrived so soon and this surprised her very much)

\section{E. Dialectical Thinking VS Logical Thinking}

Another specialty of the Chinese thinking mode lies in the dialectical elements. The Chinese seldom consider things isolate but rather dialectical. The easiest instance is the Chinese phrase “舍得” (“afford to lose” in the common sense) which actually implies that you should first of all offer something to others if you mean to get something back. To give and to take are two opposite actions but in Chinese the contradictory actions are combined in one phrase “舍得” — to take by giving. The English have strict sense of logic and things are black or white, no middle position or combination of the two.

\section{LINGUISTIC DifFERENCES RESULTING FROM DIFFERENCES OF THINKING PATTERNS}

The effect of different thinking modes on linguistic construction is also apparent in the lexical, syntactic, contextual and grammatical features of the two languages.

\section{A. Lexical Differences}

English word formation takes various forms such as affixation, compounding and conversion, blending, clipping acronyms, backformation and adoption from proper nouns. But Chinese words (characters) never experience such formation process. Their grammatical functions and meanings are decided by their relations with other words (characters) in their context and are thus more flexible and context-dominated. In English, we have "we, our, us, ours" and "I, my, me, mine" for the first personal, but in Chinese we have only one word (character) "我” (I, me) and by adding another word “的”, we get the phrase “我的” (my or mine) to indicate the possessive relationship or adding “们” to get “我们” (we or us) for the plural form of “我” and we can get another phrase “我们的” by adding both words “们” and “的” after “我” to get the plural possessive form of the word “我”. This implies that the Chinese morphemes enjoy more liberal combination with other morphemes to establish new and more complicated phrases. But the English morphemes, when forming new words, or even conducting different grammatical functions, will follow strict rules and even take completely new forms.

Such differences in lexical features have also caused great trouble to translators. Actually in too many cases translation is impossible, and the original meaning is only partly conveyed via metaphor or explanation as no other alternative is available for such translation. 


\section{B. Syntactic Features}

Wang Yin, the famous professor once said that some linguistics lively compare English structure as "grape structure", for the trunk of the grape is very short with many fruit attached on it to form very long sentences. Different from that, the Chinese sentences are shorter with phrases in sequential order by themselves just like the bamboo joints. So Chinese is called "bamboo structure". (Hu Wenzhong, 1999)

The most commonly used word order for English is the strict SVO. English sentences take verbs as their cores, which are their center controlling all the relationships between the sentence components. Except the predicate verb all the verbs take the form of indefinite form to make difference from the predicate verb, and many prepositions and conjunctions are used to connect the phrases contained. For Chinese it usually makes good use of verbs together in one sentence to present the things one by one according to the time when the things happened.

\section{Semantic Features}

The semantic features of English and Chinese thinking modes can be analyzed in two sub-sections: the intra-sentence relationship and the inter-sentence relationship. The former refers to the relationship among different parts within a sentence and studies the way that different parts are composed to establish meaningful sentences. The latter, in a broader sense, tends to expose the relationship between or among different sentences and how they are related to each other to convey the author or speaker's intentions. Yet the latter, inter-sentence relationship is different from contextual relationship in that contextual relationship studies such relationship in light of whole paragraphs or even whole passages while inter-sentence relationship is more sentence-oriented.

1. Intra-sentence Relationship:

Even within a sentence, the Chinese would rather shift from the general information to the more specific and detailed and would usually give the minor information before focusing on the key points. This well embodies their thinking patterns such as tortuous thinking and subject-oriented etc.

S4A：为了保障涉外经济合同当事人的合法权益，促进我国对外经济关系的发展特制定本法。

S4B: This law is formulated with a view to protecting the lawful rights and interests of the parties to Chinese-foreign economic contracts and to promoting the development of China's foreign economic relations.

The Chinese sentence introduces the objectives in great detail before bringing out the key point of the whole sentence, but the English translation, instead, begins with the focus------the law is formulated----before offering the objective and other minor information. When reading the Chinese sentence, we can also find that the speaker is more concerned with the law-maker's consideration in making the law while the English emphasized the fact that the law has been formulated and shall be duly implemented.

2. Inter-sentence Relationship:

The relationship among sentences is also different between Chinese and English. As the Chinese are hypotaxis-oriented while the English are parataxis- considerate, Chinese sentences are usually more distant from each other in connotation and demand few conjunctive phrases, thus offering the speaker or writer greater freedom in thought and composition. To sum up, the Chinese inter-sentence relationship are more like a brook flowing freely. E.g.

S5: We don't understand that pain may be telling us that we are eating too much or the wrong thins, or that we are smoking too much or drinking too much, or there is too much emotional congestion in our lives, or that we are being worn down by having to cope daily with overcrowded streets and highways, the pounding noise of the garbage grinders, or the cosmic distance between the entrance to the airport and the departure gate.

Long as the whole sentence may be, the frame is but a simple SVO structure followed by some parallel clauses or short semantic segments connected by some "ors". The structure is clearly outlaid and the relationship between clauses readily comprehensible.

S6A: 苏州城内外有许多古老园林, 其中十几个作为古迹保留下来向公众开放。它们是中国传统山水园林建筑 的精华之作，融诗歌、绘画、园林于一体。

When translating the above paragraph about Suzhou, we have to add some functional, esp. conjunctive phrases so as to realign the original segmented loose clauses into well-structured full sentences dominated by some core semantic units, and the reading thus reads:

Inside and outside the city are scattered many classical gardens, over a dozen of which are being preserved as historical monuments open to the public. They represent the cream of traditional Chinese landscape architecture that integrates poetry, painting, and landscape gardening.

It's necessary to mention that hypotaxis here refers to the integration among sentences and phrases by means of functional and grammatical components. Parataxis is the connection by means of the connotations of the semantic units rather than by means of external functional components. Cohesion is the focus in hypotaxis whereas coherence is the main concern in parataxis.

\section{Contextual Features}

Also based on the Chinese hypotaxis-tended thinking mode and their dialectical consideration in expressions, the contextual features in Chinese writing or speech are also apparently different from the English. The Chinese do not pay so much attention to the external connection among sentences but the sentences join themselves by the internal 
correlations logically and semantically. The English, in contrast, pay great attention to the formal connection among sentences and use various conjunctive phrases to indicate the logic relationship in the context. Therefore, reading Chinese paragraphs, the reader will have to understand the author on basis of the whole context so as to get a thorough and comprehensive understanding of the paragraph or the essay. The readers of English passages will not be so burdened.

S7A：十月五日第 ot-5 号合同项下的 20 万吨大米，原定于十二月底前交货。你放在合同中保证提前交货，并 且以此作为签订合同的条件，但是，这批大米迄今尚未装运，对此我们深表遗憾。

This is a typical business message in which the author presents the background information for his claim and then offers two evidences for it and finally puts forward the claim. Such sequence is typical of Chinese thinking modes, but if literally rendered, it reads:

S7B: The 200000 tons of rice under Contract No. OT-t of October 5 is scheduled to be delivered by the end o December. You have guaranteed an early delivery in the Contact and it is on this understanding that we signed the contract. Up to now however, the shipment has not yet been made. We very much regret for that.

Such literal translation in conformity with the Chinese sequence of thoughts, is loose in structure and logic and is lacking in theme, making the whole passage appears confusing. But native English speakers would prefer to express the same as follows:

S7C: We very much regret that the 200000 tons of rice under Contract No. OT-5 of October 5 , scheduled to be delivered by the end of December, is up to this moment not dispatched, in spite of the fact that you have guaranteed an early delivery in the Contract which as actually signed on this understanding.

In S7C, the speaker/author begins with the theme of his writing-----to claim on the failure of delivery of the 20000 tons rice, which will sound natural and readily acceptable and comprehensible to native English speakers. The sequence of thoughts, the purpose and the reasoning are all well composed.

A brief comparison will indicate that there are not only syntactic changes in the translation but also great changes in the viewpoints of narration, esp. in those sentences without subject in the Chinese original story.

The internal logic relations among semantic segments are not clearly or directly stated in the Chinese but rather indicated by the context and have to be recognized by the reader. Yet in the English, it's always necessary to state the relationship clearly or the sentences would sound awkward or meaningless. The reason for these is the difference in the thinking modes of the Chinese and that of the English.

\section{E. Grammatical Features}

Due to the English people's emphasis on objective observation and the Chinese nation's focus on subject perceptions, sentence with an inanimate subject or in passive voice are more popular in English while the Chinese prefer active voice or sentences without subject. E.g.

S8A: Yet the Nile has been changed by modern man in ways not yet fully understood.

S8B: 然而现代人却使尼罗河发生了变化, 不过就连他们自己也不完全了解尼罗河就近发生了什么变化。

In some other grammatical aspects, Chinese has no grammatical changes in the morphemes while it is just too common in English to change the forms of words for different grammatical functions. Referring to almost any Chinese writing and comparing it with similar English version, we have little or no difficulty finding abundant instance to this effect.

\section{Some Strategies to Overcome The Chinglish Writing}

There are a lot of differences in the writing style of the English and Chinese languages in the way of thinking, discourse structure and language features. Combining with the practice of English teaching and analyzing the Chinese writing style in the Chinese students' compositions, we believe that only the students are familiar with and master the Western mindset and make the paradigm shift consciously in the process of writing in English, can they write authentic English essays. We should do the following in our teaching and learning:

\section{A. Develop Students' Cross-cultural Awareness.}

Kaplan (1966) believes that students from different cultural backgrounds use different modes of written language, which is due to the negative transfer of the mother tongue. Guo Chunjie and Liu Fang (1997), studying the output process of second language learners, found that most of the reasoning of second language learners in the target language output is assumed due to the mother tongue. Therefore, we should compare the different ways of thinking in Chinese and English in conjunction with the teaching contents to enable students to understand the differences of Chinese and English thinking to improve cross-cultural awareness and cultivate their English cultural sensitivity to overcome the impact of Chinese thinking in English learning process.

\section{B. Attention to Discourse Teaching.}

First, by purposeful reading training and detailed analysis, we can enable students to understand the different characteristics of the Chinese-English mode of thinking. According to the study, the students' English reading ability and discourse knowledge of have indirect effects on their English writing (Ma Guanghui, Wen Qiufang, 1999). 
Therefore, wasting no time to introduce the discourse knowledge in reading training will have a positive impact on the improvement of English writing ability. Then we should conduct targeted writing trainings to train students to use the English way of thinking to organize their minds and to construct the framework of their articles.

\section{Train Students to Construct the Connection of English Discourse with the Formal Logic Thoughts.}

Because the Chinese students are influenced by dialectical thinking, they usually write English thesis with "agreeing in opinion", lacking conjunctions in sentence borders among paragraphs. Readers will have a jumping and incoherent feeling to the article, thus causing the difficulty in understanding and affecting the quality of the article. Therefore, in the writing teaching, the teacher should train students to construct the engagement of discourse with the logical thinking and encourage students to use the conjunctions to strengthen the continuity of their thesis appropriately. To realize the engagement of macroscopic discourse, students should use discourse mark conjunctions expressing the meanings of progressive, enumerates, transition, contrast, degree, causal relation, summary as well as analysis and conclusion so as to manifest the engagement and linking-up of discourse.

In the daily teaching, teacher can train students to use the discourse conjunctions from two aspects. First, teachers can ask students to recite the above mentioned discourse mark conjunctions expressing progressiveness, contrast, cause and effect and so on. For example, conjunctions of contrast like however, nevertheless, differ from, in contrast to on the contrary, on the other hand, in opposition to, etc. Conjunctions of cause and effect like so, thus, therefore, accordingly, owing to, thanks to, out of, there as on for, the cause of, it follows that and so on. In memorizing these different expressions, students will be able to come in handy to use them, and the convergence effect of their composition will be significantly improved and enhanced.

On the other hand, teachers can devise some practices of this aspect to train students. Take the following paragraph as an example: He was a delinquent in many ways. His mother loved him. He was a truant. He was arrested for breaking street lights. He stole a car. He was a bully in the school. He was intelligent. He made poor grades. His mother was worried and hurt. She never let him know. She was there. She believed in him. She let him know it. He never felt deserted. She stood behind him. He reformed. A mother's love paid off.

The above paragraph appears disorganized and the meaning of the expression is not clear because of the lack of conjunctions. Students are required to add appropriate conjunctions to achieve coherence so the improved paragraph is as follow: Although he was a delinquent in many ways, his mother still loved him. Even though he was a truant and was once arrested for breaking street lights, his mother kept right on loving him. At one time, he even stole a car. In addition, he was bully in school, and although he was intelligent, he still made poor grades. Even if his mother was worried and hurt, she never let him know. She was always there. She believed in him, and she let him know it. He never felt deserted because she always stood behind him. Finally, he reformed. A mother's love, in this case, paid off.

The revised paragraph by adding the necessary conjunctions becomes fluent and coherent. Such exercises can enhance students' ability of applying the connections and improve their English writing competence.

\section{Practical Application of Grammar Teaching and the Cultivation of Students'Language Ability.}

China's traditional English teaching focuses on grammar but ignores language application ability of students. Students only mechanically gained the vocabulary and rules of grammar, lacking the feeling and understanding of the language, far from understanding the thinking characteristics of Chinese and English languages, and as a result, lacking the ability of practical application of language. English grammar teaching can not just stay in listing the rules of grammar but make comparison of the different expressing methods of English and Chinese, and convert the two ways of thinking consciously in English writing. In short, there are many factors that affect students' English writing, but if teachers lay emphasis on different modes of thinking, find the corresponding countermeasures and give students targeted training in English writing, students will be able to receive good results in their writing practice.

\section{CONCLUSION}

Chinese students can not rid themselves of the participation of the mother tongue in their English writing. A lot of mistakes in the Chinese students' writing are caused due to the interference of the Chinese thinking. Therefore, if the Chinese students want to write good articles in English, they should be aware of the Anglo-American culture on the one hand, to improve the ability to master the language. On the other hand, they should also pay attention to the differences in English and Chinese thinking modes and how they influence the language application. Students should be familiar with the laws of English writing, learn to use English thinking mode to organize materials, thus reducing Chinglish in articles and being able to write to meet the requirements of writing.

\section{REFERENCES}

[1] Deng Yanchang \& Liu Runqing. (1989). Language and Culture. Beijing: Foreign Language Teaching and Research Press.

[2] Guo Chunjie \& Liu Fang. (1997). A Dynamic Research into L1 Influence on L2 Writing. Modern Foreign Language, 4, $30-38$.

[3] Hu Wenzhong. (1999). Aspects and International Communication. Beijing: Foreign Language Teaching and Researching Press.

[4] Joseph A. Devito. (2001). The Interpersonal Communication Book. London: Langman.

[5] Kaplan, R. (1966). Cultural Thought Patterns in Intercultural Education. Language Learning, 2, 15-27. 
[6] Kaplan, R. (1972). Argument Translation Networks as Psychological Models of Sentence Comprehension. Artificial Intelligence, 3, 77-100.

[7] Kelly, G. (1963). The Theory of Personality: Psychology of Personal Construct. New York: W. W. Norton Company.

[8] Kobayashi, H. \& Rinner, C. (1992). Effects of First Language on Second Language Writing: Translation versus Direct Composition. Language Learning, 42, 256-273.

[9] Larry A. Samovar, Richard E. Porter and Lisa A. Stefani. (2000). Communication between Cultures. Beijing: Foreign Language Teaching and Researching Press.

[10] Lian Shuneng. (1993). Contrastive Studies of English and Chinese. Beijing: Higher Education Press.

[11] Ma Guanghui \& Wen Qiufang. (1999). Research on the Influence Factors of College Students' English Writing Ability. Foreign Language Teaching and Researching, 4, 34-39.

[12] Scollon, R. \& Wong Scollon, S. (1991). Topic Confusion in English-Asian Discourse. World Englishes, 10(2), 113-126.

Ying Wang was born in Tangshan, China in 1978. She received her M. D in linguistics from Dongbei University of Finance and Economics, China in 2009.

She is currently an instructor in Hebei United University, Tangshan, China. Her research interests include business English and linguistics.

Jing Chen was born in Tangshan, China in 1978.

She is currently an instructor in Tangshan Vocational and Technical College, Tangshan, China. Her research interests include business English and linguistics. 